\title{
Effect of ambient air pollution on premature SGA in Changzhou city, 2013- 2016: a retrospective study
}

\author{
Shushu $\mathrm{Li}^{1 \dagger}$, Huaiyan Wang ${ }^{2 \dagger}$, Haiting $\mathrm{Hu}^{2 \dagger}$, Zeying $\mathrm{Wu}^{3}$, Kejin Chen ${ }^{2}$ and Zhilei Mao $2,45^{*}$ (D)
}

\begin{abstract}
Background: Air pollution is becoming an increased burden to the world. Previous studies have confirmed its effects on adverse birth outcomes, but few associated with premature small for gestational age (SGA). We report a retrospective cohort study conducted in Changzhou city to evaluate the association between air pollutants (PM 2.5 , $\mathrm{SO}_{2}$ and $\mathrm{NO}_{2}$ ) and premature SGA during pregnancy.

Methods: A total of 46,224 births were collected from January, 2013 to December, 2016, in Changzhou Maternity and Child Health Care Hospital, finally 2709 preterm births were admitted for study. Corresponding air monitoring data were collected from Changzhou Environmental Protection Agency. Generalized estimating equations were used to examine the association between these air pollutants and premature SGA controlling for individual covariates in single- and multi-pollutant models.
\end{abstract}

Results: We found that, in the third trimester, every $10 \mu \mathrm{g} / \mathrm{m}^{3}$ increments in $\mathrm{PM}_{2.5}$ concentration were associated with premature SGA $(\mathrm{OR}=1.18,95 \% \mathrm{Cl}: 1.03-2.83 ; \mathrm{OR}=1.37,95 \% \mathrm{Cl}: 1.03-3.58)$ in two- and three-pollutants models. In the whole gestation, a $10 \mathrm{\mu g} / \mathrm{m}^{3}$ increment in $\mathrm{PM}_{2.5}$ concentration in two- and three-pollutant models were related to premature SGA (OR=1.53,95\% Cl: 1.38-2.47; $\mathrm{OR}=1.73,95 \% \mathrm{Cl}: 1.18-2.57)$. The $\mathrm{OR}(95 \% \mathrm{Cl})$ of premature SGA were increasing across quintiles of $\mathrm{PM}_{2.5}, \mathrm{SO}_{2}, \mathrm{NO}_{2}$ concentrations during the whole gestation period adjusting for confounders $(P$ for trend $<0.001)$.

Conclusions: These results indicated that pregnant women exposed to $\mathrm{PM}_{2.5}$, combined with other pollutants in the third trimester have a higher risk to deliver premature SGA babies, providing further evidence linking $\mathrm{PM}_{2.5}$ and pregnancy outcomes.

Keywords: Air pollution, Premature SGA, Exposure windows, Retrospective study

\section{Background}

With the rapid development of economy, air pollution has become a serious public health problem, and gained much global attention. A variety of studies have revealed the association of air pollution with many human diseases, such as respiratory infections [1], cardiovascular diseases [2], Parkinson's disease [3], and depression [4], These diseases generated a large burden of mortality and

\footnotetext{
* Correspondence: mao598808386@126.com

†Shushu Li, Huaiyan Wang and Haiting Hu contributed equally to this work. ${ }^{2}$ Changzhou Maternity and Child Health Care Hospital affiliated to Nanjing Medical University, Changzhou 213003, Jiangsu, China

${ }^{4}$ State Key Laboratory of Reproductive Medicine, Center for Global Health, Nanjing Medical University, 101 Longmian Road, Nanjing 211100, China Full list of author information is available at the end of the article
}

years of life lost $[5,6]$. More recently, an increasing number of researches $[7,8]$ have indicated the potential associations between air pollutants exposure and the adverse pregnancy outcomes and mortality. Generally, adverse birth outcomes and fetal health during pregnancy could be evaluated by some common indicators including growth restriction, also known as small for gestational age (SGA), which was defined as a birth weight below the 10th percentile for the same gestational age by sex; preterm birth (PTB), defined as a live birth before the 37th week of gestation; and low birth weight (LBW), defined as a birth weight less than $2500 \mathrm{~g}$. Air pollutants were reported had adverse impacts on fetal development in both animal and human studies $[9,10]$. 
Epidemiological studies mainly focused on PTB [11-13], SGA [14] and LBW [15-17]. A literature from [18] reviewed the association between air pollutants (including particulate matters below 10 and $2.5 \mu \mathrm{m}$ in aerodynamic diameter $\left(\mathrm{PM}_{10}\right.$ and $\left.\mathrm{PM}_{2.5}\right)$, nitrogen dioxide $\left(\mathrm{NO}_{2}\right)$, sulphur dioxide $\left(\mathrm{SO}_{2}\right)$, and carbon monoxide $(\mathrm{CO})$ ) and adverse birth outcomes (low birth, LBW and PTB). Another recent research [19] indicated that exposure to high concentrations of $\mathrm{PM}_{2.5}$ in the second trimester and exposure to $\mathrm{PM}_{10}$ in the late pregnancy had a strong effect on PTB. Le et al. [20] also found that SGA was associated with $\mathrm{CO}$ levels exceeding $0.75 \mathrm{ppm}$ and $\mathrm{NO}_{2}$ exceeding $6.8 \mathrm{ppb}$ exposure in the first month. Although some studies had confirmed the significantly impacts of air pollutants on PTB and SGA, few studies had elucidated the relationship between air pollutants and premature SGA. However, whether they would affect the premature SGA is still unclear.

Therefore, this study set to address this important question. It has been realized that the nature of the components in particulate matters mainly depend on local natural environment, industrial types and meteorological conditions, and that different composition would impose different effects [21]. Given that the $\mathrm{PM}_{2.5}$ components differ among different regions, local studies could not be replaced by those performed in other regions. In addition, the genetic variation of different populations is known to be associated with different responses to the environmental risks [22], so the European or African population studies reported may not represent the situation in the Asia population.

In this study, we recruited only the premature birth and analyzed the associations between premature SGA and air pollutions in Changzhou city, and excluded other factors which may affect premature on SGA.

\section{Methods}

\section{Study population}

Our study subjects were obtained from a retrospective study of the premature infants and their mothers from
Changzhou Maternity and Child Health Care Hospital affiliated to Nanjing Medical University during 20132016. Women below 37 weeks of gestational durations were enrolled in the birth registry. Birth records included the data of infant gender, date of birth, gestational age, birth weight, birth order, number of stillborn (if multiple births), maternal age at child's birth, total number of live born and stillborn (ever). Maternal behaviors including smoking and alcohol consumption were not available. Small for gestational age (SGA) were defined as $<10$ th percentile of birth weight of gestational age. The first trimester of pregnancy was defined as gestational week 1 to 12 , the second trimester as week 13 to 27 and the third trimester as from week 28 to birth.

\section{Exposure assessment}

In this study, daily air pollutants $\left(\mathrm{PM}_{2.5}, \mathrm{SO}_{2}\right.$ and $\left.\mathrm{NO}_{2}\right)$ concentrations were simultaneously collected from seven fix-sited air pollution monitoring stations in Changzhou, including Chengjian school, Anjia, Wujin, Lucheng, Changgongyuan and Changzhou city from January 1, 2013 to December 31, 2016 in Changzhou Environment Protection Agency. The inverse distance weighting (IDW) method was performed by a geographic information system (ARCGIS, version 10.3; ESRI, Redlands, CA, USA) according to the following procedures. First, the residential address of each pregnant women registered in the medical records was transferred into longitude and latitude using xGeocoding software. Researchers indicated the monitoring data could represent a good indicator of individual exposure if subjects resided less than $40 \mathrm{~km}$ from the nearest station. And the minimum and maximum distance from individuals' residence addresses to the nearest monitoring station were measured at 0.04 and $29.44 \mathrm{~km}$, respectively, in our study. Then, an appropriate spatial resolution $(100 \mathrm{~m})$ was used to divide study areas into $100 \mathrm{~m} \times 100 \mathrm{~m}$ grid cells (Rivera-González et al., 2015). Finally, we used the inverse squared distance (1/squared distance) to weight the monitoring data of the nearest station and the coordinates
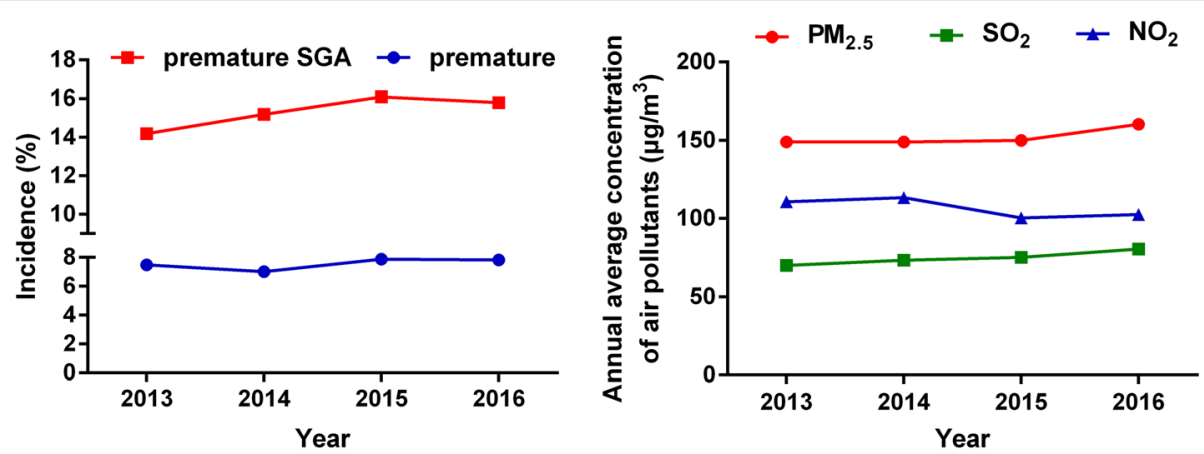

Fig. 1 The median concentrations of air pollutants and incidences of premature SGA from 2013 to 2016. SGA: small for gestational age, PM2.5: particular matter 2.5, $\mathrm{NO}_{2}$ : nitrogen dioxide, $\mathrm{SO}_{2}$ : sulphur dioxide 


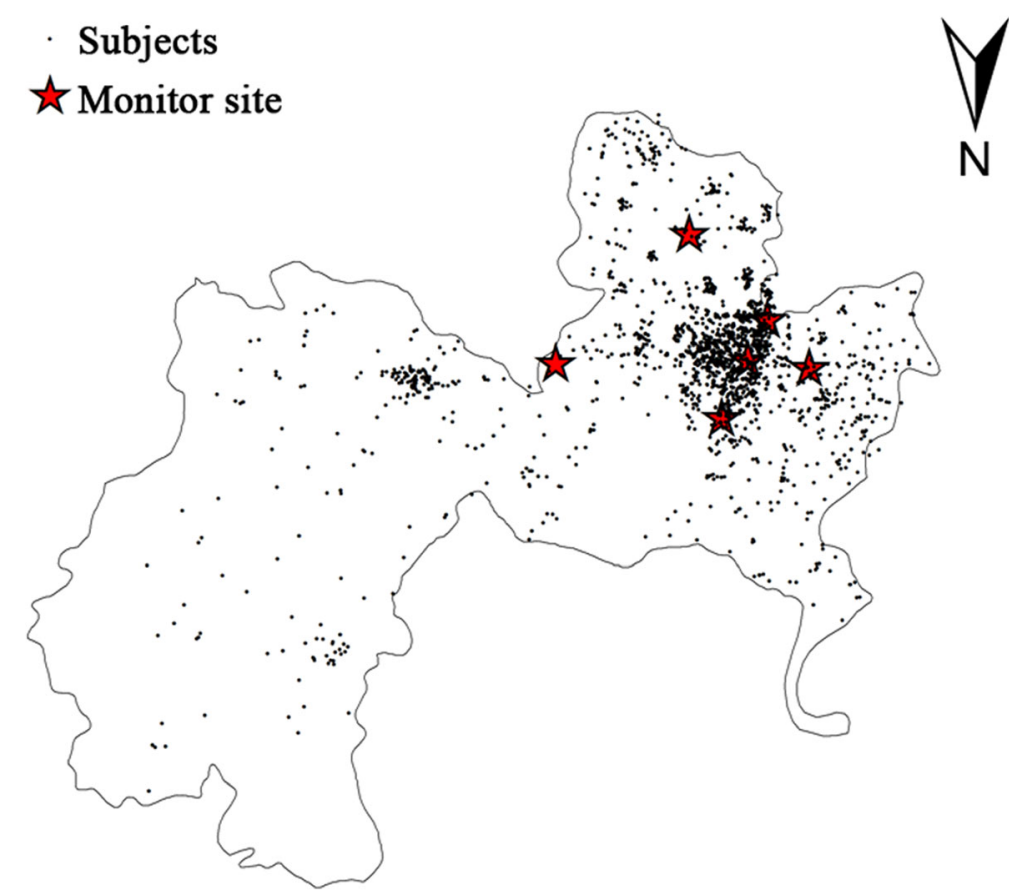

Fig. 2 Location of monitoring sites and subjects. Six monitoring sites and 2709 pregnant women with premature births were marked by red pentagrams and black solid dots, respectively. The map was generated by the professional software (ARCGIS, version 10.3; ESRI, Redlands, (A, USA)

of subjects were applied to calculate the daily pollution levels. The gestational age and birth date were used to calculate trimester-specific and entire pregnancy periods. The air pollution measurements were integrated into monthly summaries.
We used an inverse distance weighting approach to predict residential sites across Changzhou. For each birth, the pregnancy and trimester-specific pollution exposure measurements were calculated by monthly summaries. Data from the six monitoring stations were included in each

Table 1 Summary of estimated air pollutants by exposure period

\begin{tabular}{|c|c|c|c|c|c|c|c|c|c|c|}
\hline \multirow[t]{2}{*}{ Pollutant $\left(\mu \mathrm{g} / \mathrm{m}^{3}\right)$} & \multirow[t]{2}{*}{ Mean } & \multirow[t]{2}{*}{ SD } & \multicolumn{8}{|c|}{ Percentile } \\
\hline & & & Min & 5 th & 25th & 50th & 75th & 95th & Max & $\mathrm{IQR}^{\mathrm{b}}$ \\
\hline \multicolumn{11}{|l|}{$\mathrm{PM}_{2.5}$} \\
\hline Trimester1 & 39.80 & 31.82 & 5.72 & 30.95 & 41.12 & 53.97 & 66.88 & 77.58 & 98.43 & 25.76 \\
\hline Trimester2 & 53.63 & 20.68 & 9.08 & 37.42 & 49.29 & 60.31 & 66.91 & 78.51 & 90.65 & 17.61 \\
\hline Trimester3 & 59.98 & 15.62 & 7.19 & 36.34 & 46.15 & 61.43 & 70.79 & 83.17 & 95.17 & 24.64 \\
\hline Whole gestation & 51.11 & 16.03 & 12.32 & 25.67 & 37.40 & 53.75 & 63.85 & 74.19 & 86.94 & 26.45 \\
\hline \multicolumn{11}{|l|}{$\mathrm{SO}_{2}$} \\
\hline Trimester1 & 21.37 & 16.57 & 8.52 & 12.37 & 16.45 & 28.41 & 34.88 & 42.25 & 50.57 & 18.43 \\
\hline Trimester2 & 26.21 & 10.50 & 10.88 & 15.86 & 22.50 & 28.96 & 33.10 & 38.32 & 48.01 & 10.60 \\
\hline Trimester3 & 28.82 & 8.27 & 10.05 & 16.10 & 23.44 & 30.33 & 34.04 & 41.69 & 48.31 & 10.59 \\
\hline Whole gestation & 25.46 & 8.52 & 5.44 & 11.31 & 18.82 & 26.45 & 32.72 & 37.38 & 45.51 & 13.90 \\
\hline \multicolumn{11}{|l|}{$\mathrm{NO}_{2}$} \\
\hline Trimester1 & 28.03 & 22.30 & 9.24 & 21.85 & 32.00 & 40.09 & 46.68 & 52.05 & 78.89 & 14.68 \\
\hline Trimester2 & 34.62 & 14.99 & 10.07 & 12.63 & 24.40 & 39.91 & 45.50 & 50.79 & 57.13 & 21.10 \\
\hline Trimester3 & 43.08 & 7.24 & 10.02 & 33.37 & 39.96 & 43.95 & 46.99 & 52.33 & 57.47 & 7.03 \\
\hline Whole gestation & 35.23 & 10.50 & 11.47 & 15.33 & 27.95 & 38.12 & 43.72 & 49.12 & 57.44 & 15.77 \\
\hline
\end{tabular}

SD: standard deviation, Min: minimum; Max: maximum, IQR: interquartile range

$\mathrm{PM}_{2.5}$ : particular matter $2.5, \mathrm{NO}_{2}$ : nitrogen dioxide, $\mathrm{SO}_{2}$ : sulphur dioxide 
Table 2 Descriptive statistics of SGA and mean exposure over the entire pregnancy among characteristics of the included 2709 preterm births

\begin{tabular}{|c|c|c|c|c|}
\hline Characteristic & $\mathrm{SGA}^{\mathrm{a}}[\mathrm{n}(\%)]$ & Mean $\mathrm{PM}_{2.5}\left(\mu \mathrm{g} / \mathrm{m}^{3}\right)$ & Mean $\mathrm{SO}_{2}\left(\mu \mathrm{g} / \mathrm{m}^{3}\right)$ & Mean $\mathrm{NO}_{2}\left(\mu \mathrm{g} / \mathrm{m}^{3}\right)$ \\
\hline \multicolumn{5}{|l|}{ gender } \\
\hline male & $250(9.4)$ & 51.22 & 76.55 & 105.75 \\
\hline female & $189(7.1)$ & 50.98 & 76.12 & 105.55 \\
\hline$P$ & $0.000 *$ & 0.849 & 0.725 & 0.354 \\
\hline \multicolumn{5}{|c|}{ Maternal age (years) ${ }^{b}$} \\
\hline$<20$ & $16(0.6)$ & 48.85 & 72.73 & 105.36 \\
\hline $20-30$ & $296(11.4)$ & 51.05 & 76.33 & 105.82 \\
\hline $30-40$ & $112(4.3)$ & 51.51 & 76.66 & 104.65 \\
\hline$>40$ & $7(0.3)$ & 50.77 & 75.76 & 108.82 \\
\hline$P$ & $0.000 *$ & 0.290 & 0.458 & 0.666 \\
\hline \multicolumn{5}{|l|}{ Birth years } \\
\hline 2013 & $32(1.2)$ & 49.75 & 70.29 & 110.77 \\
\hline 2014 & $130(4.0)$ & 49.70 & 73.64 & 113.37 \\
\hline 2015 & $136(4.8)$ & 50.05 & 75.43 & 100.40 \\
\hline 2016 & $141(5.2)$ & 53.48 & 80.72 & 102.55 \\
\hline$P$ & 0.747 & 0.079 & 0.279 & 0.571 \\
\hline \multicolumn{5}{|l|}{ Season of birth } \\
\hline Spring & $96(3.5)$ & 52.06 & 77.91 & 103.21 \\
\hline Summer & $105(3.9)$ & 46.87 & 67.37 & 101.65 \\
\hline Fall & $126(4.7)$ & 51.85 & 77.68 & 107.75 \\
\hline Winter & $112(4.1)$ & 53.19 & 81.47 & 109.05 \\
\hline$P$ & 0.562 & $0.001^{*}$ & $0.000 *$ & $0.000 *$ \\
\hline \multicolumn{5}{|l|}{ Natural delivery } \\
\hline No & $110(4.1)$ & 49.43 & 74.13 & 104.31 \\
\hline Yes & $329(12.1)$ & 52.42 & 78.10 & 106.71 \\
\hline$P$ & $0.000 *$ & 0.549 & $0.000 *$ & 0.127 \\
\hline \multicolumn{5}{|l|}{ Parity } \\
\hline Once & $151(5.6)$ & 50.68 & 75.43 & 106.23 \\
\hline Twice or more & $288(10.6)$ & 51.68 & 77.37 & 105.97 \\
\hline$P$ & $0.000 *$ & 0.368 & 0.715 & 0.729 \\
\hline
\end{tabular}

a SGA: small for gestational age

b missing 58 subjects

* $P<0.05$

interpolation. At last, we counted the average value of individual exposure level in each trimester and whole pregnancy.

\section{Covariates}

Individual characteristics in the analyses included maternal age at delivery (categorized into $<20,20-30,30-40$, $>40$ years old), gestational age (continuous), parity (the numbers of pregnancy, once or more than once), natural delivery or not, sex of infants (male or female), birth years (from 2013 to 2016). Birth seasons were classified into Spring: March - May; Summer: June - August; Fall: September - November; and Winter: December-February.
Meteorological information, including mean temperature, relative humidity and air pressure, were obtained from the local department.

\section{Statistical analysis}

For descriptive analysis, the min, max, mean, standard deviation (SD), median, percentiles and interquartile range (IQR) were calculated for air pollutants. The correlation among different air pollutants concentrations were assessed by Spearman correlation coefficient. Potential confounders of the relationships between air pollution exposure and premature SGA were described in terms of mean (quantitative variables) or percentages (qualitative variables). In order to 
Table 3 Comparison of median exposure of air pollutants over the entire pregnancy between cases and controls among the included 2709 preterm births

\begin{tabular}{|c|c|c|c|}
\hline \multirow{2}{*}{$\begin{array}{l}\text { Air pollutants }(\mu \mathrm{g} / \\
\left.\mathrm{m}^{3}\right)\end{array}$} & \multicolumn{2}{|c|}{$\mathrm{SGA}^{*}\left(\right.$ median, SD $\left.{ }^{*}\right)$} & \multirow[t]{2}{*}{$P$} \\
\hline & Control & Case & \\
\hline \multicolumn{4}{|l|}{$\mathrm{PM}_{2.5}{ }^{*}$} \\
\hline Trimester1 & $53.97,21.71$ & $54.02,22.19$ & 0.233 \\
\hline Trimester2 & $60.27,20.42$ & $60.54,20.84$ & 0.134 \\
\hline Trimester3 & $61.32,15.52$ & $61.68,16.32$ & 0.303 \\
\hline Whole gestation & $53.59,15.84$ & $55.69,16.86$ & 0.451 \\
\hline \multicolumn{4}{|l|}{$\mathrm{SO}_{2}^{*}$} \\
\hline Trimester1 & $28.42,16.49$ & $29.49,16.77$ & 0.356 \\
\hline Trimester2 & $28.85,10.56$ & $29.62,8.22$ & 0.452 \\
\hline Trimester3 & $29.69,8.22$ & $30.38,8.68$ & 0.615 \\
\hline Whole gestation & $26.45,8.43$ & $26.67,8.92$ & 0.734 \\
\hline \multicolumn{4}{|l|}{$\mathrm{NO}_{2}^{*}$} \\
\hline Trimester1 & $39.63,22.25$ & $40.42,22.38$ & 0.493 \\
\hline Trimester2 & $39.85,14.91$ & $39.89,14.77$ & 0.547 \\
\hline Trimester3 & $44.05,7.18$ & $44.20,7.72$ & 0.265 \\
\hline Whole gestation & $38.18,10.41$ & $38.27,10.75$ & 0.944 \\
\hline
\end{tabular}

* SGA: small for gestational age; SD, Standard deviation, $\mathrm{PM}_{2.5}$ : particular matter, $\mathrm{NO}_{2}$ : nitrogen dioxide, $\mathrm{SO}_{2}$ : sulphur dioxide adjust for correlations within people belonging to the same city, a generalized estimating equations (GEE) models were used to examine the adjusted odds ratios (ORs) and 95\% confidence intervals (CIs) for premature SGA and air pollutants in each exposure windows, adjusting for covariates including infant sex, gestational age, maternal age, parity, methods of delivery, season of birth, year of birth and meteorological information. Before running model, the linearity and independence of variants were checked by Durbin-Watson and scatter plots. The multi-collinearity was tested using variance inflation factor (VIF) which was less than five for all of the independent variables. The concentration-response curves were drawn using restricted cubic spline regression model. All statistical analyses were conducted using R3.3.1 (RCorp., College Station, TX, USA).

\section{Results}

During the study period, there were 10,028 (2013), 12, 198 (2014), 10,743 (2015), and 13,255 (2016) live births, in which 750 (2013), 856 (2014), 847 (2015), and 1078 (2016) preterm births were enrolled from the retrospective cohort study. There are 107 (2013), 130 (2014), 136 (2015), and 170 (2016) preterm SGA. The overall incidence of premature was $7.48,7.02,7.88,7.83 \%$ and premature SGA was 14.2, 15.2, 16.1, 15.8\%, both of which were increased with years (Fig. 1). After further excluding the births with missing birth records and covariate data, 2709 preterm births were admitted and analysis of preterm SGA were based on 479 births. As Fig. 2

Table 4 The estimated ORs (and 95\% Cls) of SGA associated with estimated exposure levels during exposure period

\begin{tabular}{|c|c|c|c|c|c|c|c|c|c|c|c|c|}
\hline \multirow{2}{*}{$\begin{array}{l}\text { Air pollutants } \\
\text { and model }{ }^{a}\end{array}$} & \multicolumn{3}{|c|}{ Trimester 1} & \multicolumn{3}{|c|}{ Trimester2 } & \multicolumn{3}{|c|}{ Trimester3 } & \multicolumn{3}{|c|}{ Whole gestation } \\
\hline & $\overline{O R^{b}}$ & \multicolumn{2}{|c|}{$95 \% \mathrm{Cl}$} & $\mathrm{OR}^{\mathrm{b}}$ & \multicolumn{2}{|c|}{$95 \% \mathrm{Cl}$} & $\overline{O R^{b}}$ & \multicolumn{2}{|c|}{$95 \% \mathrm{Cl}$} & $\mathrm{OR}^{\mathrm{b}}$ & \multicolumn{2}{|c|}{$95 \% \mathrm{Cl}$} \\
\hline \multicolumn{13}{|l|}{$\mathrm{PM}_{2.5}\left(\mu \mathrm{g} / \mathrm{m}^{3}\right)$} \\
\hline Single-model & 1.01 & 0.47 & 3.02 & 1.34 & 0.67 & 1.98 & 1.09 & 0.67 & 1.86 & 1.03 & 0.67 & 1.31 \\
\hline$+\mathrm{SO}_{2}$ & 1.66 & 0.62 & 1.77 & 1.13 & 0.96 & 1.72 & 1.18 & 1.03 & 2.83 & 1.63 & 1.38 & 2.57 \\
\hline$+\mathrm{NO}_{2}$ & 1.37 & 0.53 & 1.86 & 1.26 & 0.68 & 1.98 & 1.03 & 0.53 & 1.26 & 1.24 & 0.74 & 2.17 \\
\hline$+\mathrm{SO}_{2}+\mathrm{NO}_{2}$ & 1.22 & 0.77 & 2.99 & 1.37 & 0.80 & 3.54 & 1.37 & 1.03 & 3.58 & 1.83 & 1.18 & 2.97 \\
\hline \multicolumn{13}{|l|}{$\mathrm{SO}_{2}\left(\mu \mathrm{g} / \mathrm{m}^{3}\right)$} \\
\hline Single-model & 1.01 & 0.58 & 2.82 & 1.04 & 0.75 & 1.57 & 0.99 & 0.61 & 1.97 & 1.00 & 0.94 & 1.25 \\
\hline$+\mathrm{PM}_{2.5}$ & 0.99 & 0.74 & 3.78 & 0.98 & 0.76 & 1.52 & 0.96 & 0.67 & 0.99 & 0.95 & 0.89 & 1.47 \\
\hline$+\mathrm{NO}_{2}$ & 1.02 & 0.59 & 1.26 & 1.03 & 0.84 & 1.83 & 0.99 & 0.48 & 1.98 & 0.99 & 0.84 & 1.57 \\
\hline$+\mathrm{PM}_{2.5}+\mathrm{NO}_{2}$ & 1.03 & 0.74 & 3.31 & 1.10 & 0.95 & 1.52 & 1.17 & 0.76 & 2.71 & 1.05 & 0.76 & 2.99 \\
\hline \multicolumn{13}{|l|}{$\mathrm{NO}_{2}\left(\mu \mathrm{g} / \mathrm{m}^{3}\right)$} \\
\hline Single-model & 1.04 & 0.80 & 2.97 & 1.24 & 0.58 & 1.67 & 1.00 & 0.92 & 1.41 & 1.00 & 0.67 & 1.94 \\
\hline$+\mathrm{PM}_{2.5}$ & 0.99 & 0.52 & 1.34 & 1.01 & 0.94 & 1.95 & 0.99 & 0.89 & 1.46 & 0.99 & 0.92 & 1.57 \\
\hline$+\mathrm{SO}_{2}$ & 1.26 & 0.66 & 1.82 & 1.01 & 0.94 & 2.97 & 1.01 & 0.95 & 2.17 & 1.14 & 0.88 & 2.18 \\
\hline$+\mathrm{PM}_{2.5}+\mathrm{SO}_{2}$ & 1.31 & 0.72 & 3.83 & 1.26 & 0.93 & 3.26 & 0.99 & 0.79 & 2.85 & 1.23 & 0.67 & 2.56 \\
\hline
\end{tabular}

SGA: small for gestational age, OR: odds ratio, $\mathrm{Cl}$ : confidence interval, $\mathrm{PM}_{2.5}$ : particular matter, NO2: nitrogen dioxide, SO2: sulphur dioxide

a. Adjusting for infant gender, maternal age $(<20,20-30,30-40,>40)$ and parity (once, twice or more), year of birth (2013, 2014, 2015 and 2016), season of birth (spring, summer, autumn, winter), gestational age, and meteorological information (mean temperature, relative humidity and air pressure) 
showed, the spatial distribution of seven air quality monitoring stations and residence addresses of 2709 premature births is were marked by black solid dots and red pentagrams, respectively, during 2013-2016.

Table 1 shows the summary statistics of air pollutants from 2013 to 2016. Compared to the air quality guidelines issued by World Health Organization (WHO), in which the standard of $\mathrm{PM}_{2.5}, \mathrm{SO}_{2}$ and $\mathrm{NO}_{2}$ are $25 \mathrm{mg} / \mathrm{m}^{3}, 20$ $\mathrm{mg} / \mathrm{m}^{3}$, and $44 \mathrm{mg} / \mathrm{m}^{3}$, respectively, their corresponding average concentrations in Changzhou were 2.0, 1.3 and 0.8 times higher during the whole pregnancy period.

The incidence of premature SGA and mean $\mathrm{PM}_{2.5}, \mathrm{SO}_{2}$, $\mathrm{NO}_{2}$ exposure by infant gender, maternal age, and other characteristics are shown in Table 2. Average birth weight was $2211.8 \mathrm{~g}(\mathrm{SD}=522.32 \mathrm{~g})$. The majority of the study population is between 20 and 40 years old (94.7\%). Seasons of birth were roughly distributed among the four seasons equally. Significant differences in SGA incidence were noted by infant gender, maternal age, delivery and parity. The seasonal levels of air pollutants exhibited to be highest in winter and lowest in summer.

The concentrations of $\mathrm{PM}_{2.5}, \mathrm{NO}_{2}$ and $\mathrm{SO}_{2}$ were relatively strongly correlated with each other, and their coefficients ranged from 0.522 to 0.905 . The entire pregnancy exposures were highly correlated with the exposures in the three trimester period (Spearman's $\mathrm{r}=$ $0.85-0.91$, data not shown). Table 3 illustrates the distributions of each pollutant in premature SGA and control groups. All three pollutants showed higher values in premature SGA group than those in premature appropriate for gestational age (AGA) group, and showed no additional statistical significance over the entire pregnancy period.

Table 4 summaries the risk incidence of premature SGA in single- and multi-pollutant models for each change in pollutant concentrations during the whole pregnancy

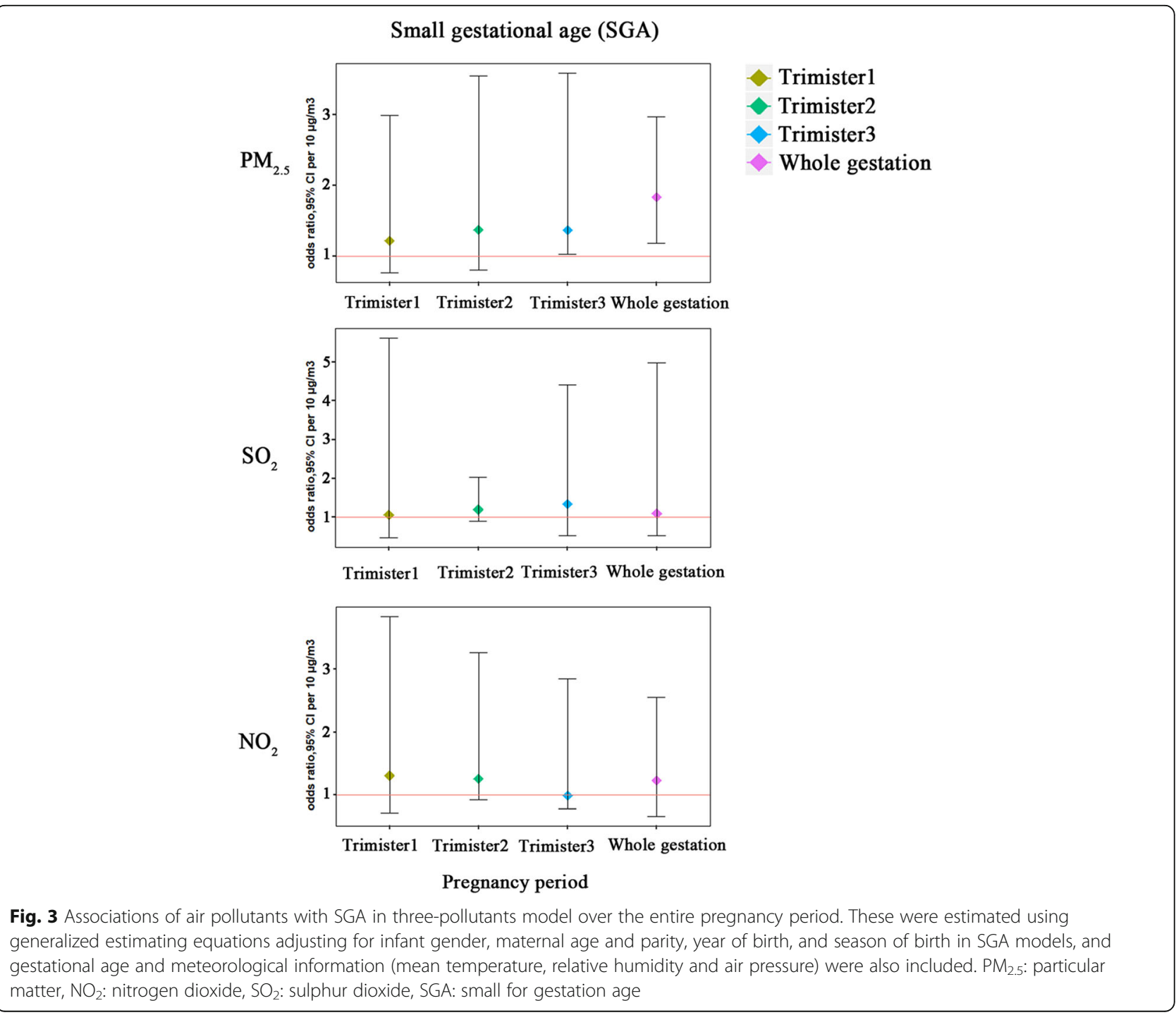


period. Figure 3 shows the associations of air pollutants with premature SGA in three-pollutant model over the entire pregnancy period, and the concentration-response curves were shown in Fig. 4. In the single-pollutant model, no significant associations were observed between premature SGA and air pollutants. The effect estimates of $\mathrm{PM}_{2.5}$ showed additional statistical significance when other pollutants were included in the models. There are positive associations with premature SGA for $\mathrm{PM}_{2.5}(p=0.016$, $\mathrm{OR}=1.18,95 \%$ CI:1.03-2.83; $p=0.009, \mathrm{OR}=1.37,95 \%$ CI:1.03-3.58, respectively) in the third trimester after adjusting confounders in two- (combined with exposure of $\mathrm{SO}_{2}$ ) and three-pollutant (combined with exposure of $\mathrm{SO}_{2}$ and $\mathrm{NO}_{2}$ ) models, in which the relative increment in risk incidence of premature SGA for each $10 \mu \mathrm{g} / \mathrm{m}^{3}$ increment in $\mathrm{PM}_{2.5}$ concentrations were 18 and 37\%, respectively during the third trimester. While in other two pregnancy periods, no significant adverse effect results were observed. In the whole gestation, the relative increase of risk incidence of premature SGA in two- (combined with exposure of $\mathrm{SO}_{2}$ ) and three-pollutant (combined with exposure of $\mathrm{SO}_{2}$ and $\mathrm{NO}_{2}$ ) models were $53 \%(95 \% \mathrm{CI}$ : 1.38-2.47) and 73\% (95\% CI:1.18-2.57) after adjustment for the potential confounders. Further, we examined the associations between $\mathrm{PM}_{2.5}$ concentrations and premature SGA in different exposure levels, as Table 5 shown, the OR $(95 \% \mathrm{CI}$ ) of premature SGA increasing across quintiles of $\mathrm{PM}_{2.5}, \mathrm{SO}_{2}, \mathrm{NO}_{2}$ concentrations during the whole gestation period adjusting for confounders $(P$ for trend $<0.001)$. The restricted cubic spline

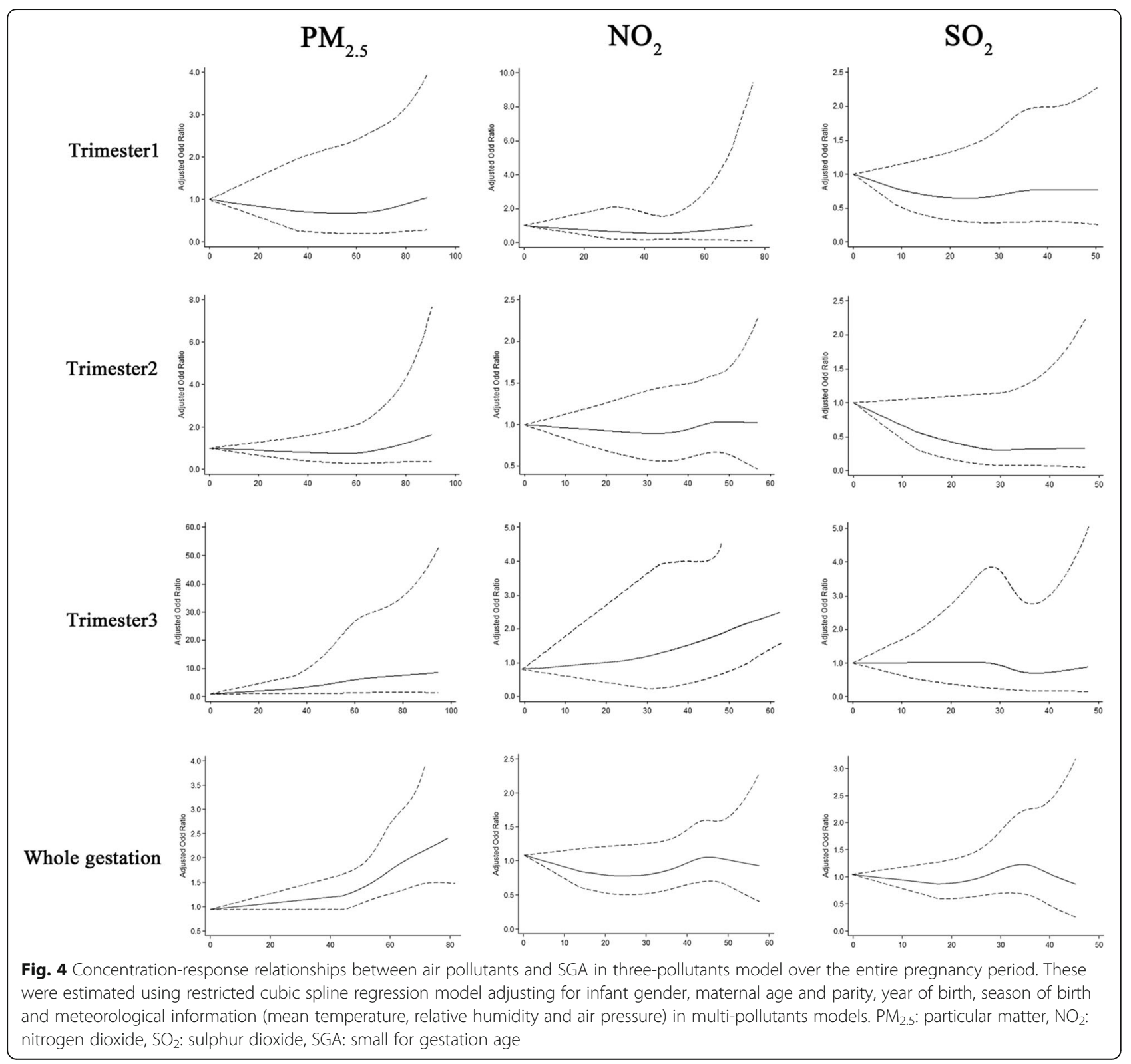


Table 5 The adjusted ORs (and 95\% Cls) of SGA according to the estimated exposure levels in three-pollutants model, for trimester specific exposure windows, among 2709 preterm births

\begin{tabular}{|c|c|c|c|c|c|c|c|c|c|c|c|c|c|}
\hline \multirow{2}{*}{$\begin{array}{l}\text { Air pollutants } \\
\text { levels }\end{array}$} & \multirow[t]{2}{*}{ NO. } & \multicolumn{3}{|c|}{ Trimester1 } & \multicolumn{3}{|c|}{ Trimester2 } & \multicolumn{3}{|c|}{ Trimester3 } & \multicolumn{3}{|c|}{ Whole gestation } \\
\hline & & $\overline{\mathrm{OR}^{\mathrm{b}}}$ & \multicolumn{2}{|c|}{$95 \% \mathrm{Cl}$} & $\overline{\mathrm{OR}^{b}}$ & \multicolumn{2}{|c|}{$95 \% \mathrm{Cl}$} & $\overline{\mathrm{OR}^{\mathrm{b}}}$ & \multicolumn{2}{|c|}{$95 \% \mathrm{Cl}$} & $\overline{\mathrm{OR}^{\mathrm{b}}}$ & \multicolumn{2}{|l|}{$95 \% \mathrm{Cl}$} \\
\hline \multicolumn{14}{|l|}{$\mathrm{PM}_{2.5}\left(\mu \mathrm{g} / \mathrm{m}^{3}\right)$} \\
\hline 1st quartile & 677 & 1.00 & - & - & 1.00 & - & - & 1.00 & - & - & 1.00 & - & - \\
\hline 2nd quartile & 677 & 1.03 & 0.76 & 1.87 & 0.83 & 0.56 & 1.34 & 1.32 & 0.80 & 2.18 & 1.05 & 0.56 & 1.64 \\
\hline 3rd quartile & 677 & 1.13 & 0.87 & 2.13 & 1.28 & 0.65 & 1.67 & 1.46 & 0.87 & 2.29 & 1.41 & 0.44 & 1.15 \\
\hline 4th quartile & 678 & 1.35 & 1.02 & 2.56 & 0.97 & 0.76 & 1.43 & 1.91 & 1.21 & 2.83 & 2.33 & 1.02 & 2.68 \\
\hline$P$ for trend & & & 0.121 & & & 0.374 & & & 0.025 & & & 0.001 & \\
\hline \multicolumn{14}{|l|}{$\mathrm{NO}_{2}\left(\mu \mathrm{g} / \mathrm{m}^{3}\right)$} \\
\hline 1st quartile & 677 & 1.00 & - & - & 1.00 & - & - & 1.00 & - & - & 1.00 & - & - \\
\hline 2nd quartile & 677 & 1.01 & 0.68 & 1.58 & 0.99 & 0.63 & 1.56 & 1.16 & 0.76 & 1.98 & 0.96 & 0.54 & 1.47 \\
\hline 3rd quartile & 676 & 1.08 & 0.71 & 1.62 & 1.30 & 0.79 & 2.01 & 1.06 & 0.65 & 1.78 & 0.98 & 0.69 & 1.87 \\
\hline 4th quartile & 679 & 0.87 & 0.53 & 1.33 & 1.36 & 0.89 & 2.31 & 1.45 & 0.91 & 2.23 & 1.06 & 0.54 & 2.92 \\
\hline$P$ for trend & & & 0.436 & & & 0.076 & & & 0.165 & & & 0.016 & \\
\hline \multicolumn{14}{|l|}{$\mathrm{SO}_{2}\left(\mu \mathrm{g} / \mathrm{m}^{3}\right)$} \\
\hline 1st quartile & 677 & 1.00 & - & - & 1.00 & - & - & 1.00 & - & - & 1.00 & - & - \\
\hline 2nd quartile & 677 & 1.17 & 0.89 & 1.83 & 1.20 & 0.77 & 1.38 & 1.01 & 0.53 & 1.17 & 0.98 & 0.89 & 1.15 \\
\hline 3rd quartile & 677 & 1.05 & 0.99 & 1.11 & 1.06 & 0.89 & 1.23 & 1.24 & 0.78 & 1.32 & 1.02 & 0.82 & 1.38 \\
\hline 4th quartile & 678 & 1.01 & 1.01 & 1.25 & 1.12 & 0.88 & 2.41 & 1.15 & 0.89 & 2.56 & 1.18 & 0.77 & 2.51 \\
\hline$P$ for trend & & & 0.657 & & & 0.175 & & & 0.078 & & & 0.004 & \\
\hline
\end{tabular}

SGA: small for gestational age, OR: odds ratio, $\mathrm{Cl}$ : confidence interval, $\mathrm{PM}_{2.5}$ : particular matter, $\mathrm{NO}_{2}$ : nitrogen dioxide, $\mathrm{SO}_{2}$ : sulphur dioxide

a. Adjusting for infant gender, maternal age $(<20,20-30,30-40,>40)$ and parity (once, twice or more), year of birth (2013, 2014, 2015 and 2016), season of birth (spring, summer, autumn, winter), gestational age, and meteorological information (mean temperature, relative humidity and air pressure)

b. OR per 10 units increase

regression model was used to evaluate the associations continuously (Table 5) and the regression splines suggested a possible threshold effect for $\mathrm{PM}_{2.5}$ concentrations of approximately $40 \mu \mathrm{g} / \mathrm{m}^{3}$ on premature SGA risk, for $\mathrm{SO}_{2}$ and $\mathrm{NO}_{2}$, the effect became flat at approximately 45 and $35 \mu \mathrm{g} / \mathrm{m}^{3}$, and these air pollutants concentrations showed linear relation with premature SGA risk.

\section{Discussion}

To our knowledge, this is the first study to focus on the relationship between air pollution and premature SGA. The IDW model were applied to evaluate precisely the air pollutant concentrations $\left(\mathrm{PM}_{2.5}, \mathrm{SO}_{2}\right.$ and $\left.\mathrm{NO}_{2}\right)$, and this retrospective cohort study explored the adverse effects of maternal exposure on fetus outcomes in Changzhou, 2013-2016. The results indicate that increased $\mathrm{PM}_{2.5}$ levels were significantly associated with higher risks of premature SGA in multi-pollutants models in the third trimester and whole gestational period.

Changzhou is a modern city but less industrialized city. Its air pollution possesses unique components, so the similar studies from other cities or regions cannot replace the local study like this one in Changzhou. We collected the pregnant data from the City Maternal and
Child Health Care Hospital, which receives half of the delivery women in the city and could fairly represent the local situation.

In this study, the incidence of premature SGA and air pollutants concentration increased by years in Changzhou, 2013-2016. A significant positive association was identified between air pollution and premature SGA, which is in accordance with many previous studies [23, 24]. Then we estimated individual exposure to $\mathrm{PM}_{2.5}, \mathrm{SO}_{2}$ and $\mathrm{NO}_{2}$ in each trimester as well as over the whole pregnancy. The data of pollutant values were interpolated into trimesterspecific and entire pregnancy. By generalized estimating equations regression models, gestational exposure to $\mathrm{PM}_{2.5}$ combined with $\mathrm{SO}_{2}$ or $\mathrm{SO}_{2}+\mathrm{NO}_{2}$ increased SGA prevalence by 18 and $37 \%$ per $10 \mu \mathrm{g} / \mathrm{m}^{3}$ increments during the third trimester, respectively. As we know, embryonic development has sensitive windows to harmful environmental substances. In the early stage of development, if the pregnant mother is exposed to pollutions, it can likely result in abortion, stillbirth or deformity [25]. In the first trimester, the exchange of substance between embryo and mother is relatively low, and the inner exposure dose of air pollutants is low, therefore, the harmful effects from exposure would be less severe. While in the third trimester when the fetus develops fast, plenty nutrition, as well 
as toxic substrates, was delivered to embryo for its rapid growth, so the internal exposure dose increased, the hazard effects may be amplified, and in this period, the toxic effects might show as hypoevolutism [26].

We observed that both prevalence of SGA and the mean concentrations of pollutants $\left(\mathrm{PM}_{2.5}, \mathrm{SO}_{2}\right.$ and $\left.\mathrm{NO}_{2}\right)$ are higher in winter and lower in summer, which was in consistent with meteorology that higher temperature facilitates cyclone and is beneficiary for the pollutants to diffuse. And women with premature fetus were those who start pregnant in winter when the air pollutants concentrations were higher. It should be noted that the above difference was not significant in this study, which might be attribute to the sample size. Further studies on this would be warranted. Air pollutants were reported to induce premature under many molecular mechanisms, including causing maternal inflammation [27], affecting placenta development [28] or inducing ROS-derived damage [29], but the mechanisms for air pollution-related premature SGA need to be further studied.

Air pollutants were complex, and could have combinational toxic effects (Šaueret al., 2018), pollutants could alter the chemical properties and enhance the toxicity of each other. For instance, $\mathrm{PM}_{2.5}$ could absorb other toxic substance and enhance their toxicity. That might explain that why there was no significant association between PM2.5 and SGA in a single model but a significant association in multi-pollutant mode in our study. Therefore, we analyzed the interaction between different pollutants, and the results showed that $\mathrm{PM}_{2.5}$ exhibits an increased risk when $\mathrm{SO}_{2}$ and/or $\mathrm{NO}_{2}$ were a combined risk(s), which was similar to the previous studies [30]. Our study also showed that $\mathrm{PM}_{2.5}$ might be the main risk factor for premature SGA, and we should set priority to low its concentration in the polluted air.

Strengths of the study included the retrospective cohort study and the accurate IDW exposure method based on the coordinate of monitoring stations and individual residential locations. However, the time spends in traffic, occupational activities and moving during pregnancy were unavailable. Although a series of potential confounders were controlled, maternal smoking and alcohol consumption, known risk factors for premature births, were excluded in this model. The main reason was that we focused on the pregnant consumption of tobacco and alcohol in every trimester pregnancy during the whole gestational period, and none was exposed. The maternal disease is also associated with premature, however, which was not adjusted for in our models since information on maternal diseases was missing for a large number of pregnant women. On the other hand, amount of important covariates was taken into account: delivery, gestational age, parity, natural delivery or not, sex of infants, birth years, birth season of birth. In addition, the positive association does not mean causality in a retrospective study.

\section{Conclusion}

In this retrospective study, we confirmed the association between premature SGA and air pollution in Changzhou city, and found that the third trimester was the window of susceptibility for the premature birth weight. We analyzed and identified the risk of several air pollutants, as well as their interactive effects, and indicated that $\mathrm{PM}_{2.5}$ contributed more risk to the premature SGA than $\mathrm{SO}_{2}$ and $\mathrm{NO}_{2}$.

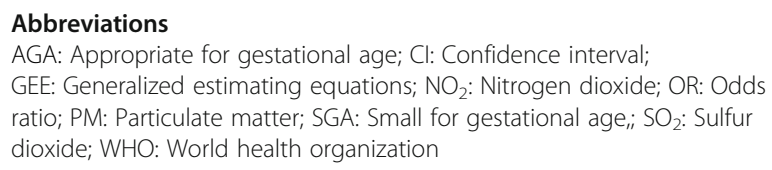

\section{Authors' contributions}

LS was responsible for the data analysis, WH supplied the original data, $\mathrm{HH}$ helped for data collection and organization, WZ and CK helped for language modifying and data checking, $M Z$ is the corresponding author and designed this study. All authors have read and approved the manuscript.

\section{Funding}

Funding supported for this study was provided by Zhilei Mao of Changzhou Maternity and Child Health Care Hospital affiliated to Nanjing medical university, Jiangsu Provincial Medical Youth Talent (QNRC2016307); The Open Project of The Key Laboratory of Modern Toxicology of Ministry of Education, Nanjing Medical University (NMUAMT201803). The founding provided the found support in data collection, analysis, linguistic revision and professional guidance.

Availability of data and materials

Data used for analysis is available upon a proper request from the corresponding author.

\section{Ethics approval and consent to participate}

This study was approved by the Ethics Committee of Nanjing Medical University, and carried out according to the international guidelines for human subjects protection. All participants were informed and signed the consent.

Consent for publication

Not applicable.

\section{Competing interests}

The authors declare no conflict of interest.

\section{Author details}

${ }^{1}$ Changzhou Center for Disease Control and Prevention, Changzhou 213022, Jiangsu, China. ${ }^{2}$ Changzhou Maternity and Child Health Care Hospital affiliated to Nanjing Medical University, Changzhou 213003, Jiangsu, China. ${ }^{3}$ Changzhou Institute of Technology, Changzhou 213003, Jiangsu, China. ${ }^{4}$ State Key Laboratory of Reproductive Medicine, Center for Global Health, Nanjing Medical University, 101 Longmian Road, Nanjing 211100, China. ${ }^{5}$ Key Laboratory of Modern Toxicology of Ministry of Education, School of Public Health, Nanjing Medical University, 101 Longmian Road, Nanjing 211100, China. 
Received: 15 March 2019 Accepted: 27 May 2019

Published online: 07 June 2019

\section{References}

1. Xia X, Zhang A, Liang S, Qi Q, Jiang L, Ye Y. The association between air pollution and population health risk for respiratory infection: a case study of Shenzhen, China. Int J Environ Res Public Health. 2017:14(9):950.

2. Mishra S. Is smog innocuous? Air pollution and cardiovascular disease. Indian Heart J. 2017;69(4):425-9.

3. Chen $\mathrm{CY}$, Hung HJ, Chang $\mathrm{KH}$, Hsu CY, Muo CH, Tsai CH, Wu TN. Long-term exposure to air pollution and the incidence of Parkinson's disease: a nested case-control study. PLoS One. 2017;12(8):e0182834.

4. Lin H, Guo Y, Kowal P, Airhihenbuwa CO, Di Q, Zheng Y, Zhao X, Vaughn MG, Howard S, Schootman M, et al. Exposure to air pollution and tobacco smoking and their combined effects on depression in six low- and middleincome countries. Br J Psychiatry. 2017;211(3):157-62.

5. Mueller N, Rojas-Rueda D, Basagana X, Cirach M, Cole-Hunter T, Dadvand P, Donaire-Gonzalez D, Foraster M, Gascon M, Martinez D, et al. Health impacts related to urban and transport planning: a burden of disease assessment. Environ Int. 2017:107:243-57.

6. Zhang Y, Peng M, Yu C, Zhang L. Burden of mortality and years of life lost due to ambient PM10 pollution in Wuhan, China. Environ Pollut. 2017;230: 1073-80.

7. Anderson JO, Thundiyil JG, Stolbach A. Clearing the air: a review of the effects of particulate matter air pollution on human health. J Med Toxicol. 2012;8(2):166-75.

8. Arroyo V, Diaz J, Salvador P, Linares C. Impact of air pollution on low birth weight in Spain: an approach to a National Level Study. Environ Res. 2019; 171:69-79.

9. Chang YC, Daza R, Hevner R, Costa LG, Cole TB. Prenatal and early life diesel exhaust exposure disrupts cortical lamina organization: evidence for a reelin-related pathogenic pathway induced by interleukin-6. Brain Behav Immun. 2019;78:105-15.

10. Guxens M, Garcia-Esteban R, Giorgis-Allemand L, Forns J, Badaloni C, Ballester F, Beelen R, Cesaroni G, Chatzi L, de Agostini M, et al. Air pollution during pregnancy and childhood cognitive and psychomotor development: six European birth cohorts. Epidemiology. 2014;25(5):636-47.

11. Murray CJ, Lopez AD. Global mortality, disability, and the contribution of risk factors: global burden of disease study. Lancet. 1997;349(9063):1436-42.

12. Gong $X$, Lin Y, Bell ML, Zhan FB. Associations between maternal residential proximity to air emissions from industrial facilities and low birth weight in Texas, USA. Environ Int. 2018;120:181-98.

13. Lavigne E, Burnett RT, Stieb DM, Evans GJ, Godri Pollitt KJ, Chen H, van Rijswijk D, Weichenthal S. Fine particulate air pollution and adverse birth outcomes: effect modification by regional nonvolatile oxidative potential. Environ Health Perspect. 2018;126(7):077012.

14. Lavigne E, Yasseen AS 3rd, Stieb DM, Hystad P, van Donkelaar A, Martin RV, Brook JR, Crouse DL, Burnett RT, Chen H, et al. Ambient air pollution and adverse birth outcomes: differences by maternal comorbidities. Environ Res. 2016;148:457-66.

15. Wallace ME, Grantz KL, Liu D, Zhu Y, Kim SS, Mendola P. Exposure to ambient air pollution and premature rupture of membranes. Am J Epidemiol. 2016;183(12):1114-21.

16. Johnson S, Bobb JF, Ito K, Savitz DA, Elston B, Shmool JL, Dominici F, Ross Z Clougherty JE, Matte T. Ambient fine particulate matter, nitrogen dioxide, and preterm birth in new York City. Environ Health Perspect. 2016;124(8): 1283-90.

17. Wylie BJ, Matechi E, Kishashu Y, Fawzi W, Premji Z, Coull BA, Hauser R, Ezzati M, Roberts DJ. Placental pathology associated with household air pollution in a cohort of pregnant women from Dar Es Salaam, Tanzania. Environ Health Perspect. 2017:125(1):134-40

18. Estarlich M, Ballester F, Davdand P, Llop S, Esplugues A, FernandezSomoano A, Lertxundi A, Guxens M, Basterrechea M, Tardon A, et al. Exposure to ambient air pollution during pregnancy and preterm birth: a Spanish multicenter birth cohort study. Environ Res. 2016;147:50-8.

19. Sagiv SK, Mendola P, Loomis D, Herring AH, Neas LM, Savitz DA, Poole C. A time-series analysis of air pollution and preterm birth in Pennsylvania, 19972001. Environ Health Perspect. 2005;113(5):602-6.

20. Le HQ, Batterman SA, Wirth JJ, Wahl RL, Hoggatt KJ, Sadeghnejad A, Hultin ML, Depa M. Air pollutant exposure and preterm and term small-for- gestational-age births in Detroit, Michigan: long-term trends and associations. Environ Int. 2012;44:7-17.

21. Vuong NQ, Breznan D, Goegan P, O'Brien JS, Williams A, Karthikeyan S, Kumarathasan P, Vincent R. In vitro toxicoproteomic analysis of A549 human lung epithelial cells exposed to urban air particulate matter and its watersoluble and insoluble fractions. Part Fibre Toxicol. 2017;14(1):39.

22. Liu J, Xie K, Chen W, Zhu M, Shen W, Yuan J, Cheng Y, Geng L, Wang Y, Li Z, et al. Genetic variants, PM2.5 exposure level and global DNA methylation level: a multi-center population-based study in Chinese. Toxicol Lett. 2017; 269:77-82.

23. Jain V, Dey S, Chowdhury S. Ambient PM2.5 exposure and premature mortality burden in the holy city Varanasi, India. Environ Pollut. 2017;226: 182-9.

24. Lamichhane DK, Leem JH, Lee JY, Kim HC. A meta-analysis of exposure to particulate matter and adverse birth outcomes. Environ Health Toxicol. 2015;30:e2015011.

25. Padberg S, Wacker E, Meister R, Panse M, Weber-Schoendorfer C, Oppermann M, Schaefer C. Observational cohort study of pregnancy outcome after first-trimester exposure to fluoroquinolones. Antimicrob Agents Chemother. 2014;58(8):4392-8.

26. Kammerlander H, Nielsen J, Knudsen T, Kjeldsen J, Friedman S, Norgard BM. Anti-TNF-alpha use during the third trimester of pregnancy in women with moderate-severe inflammatory bowel disease and the risk of preterm birth and low birth weight. Inflamm Bowel Dis. 2017;23(11):1916-23.

27. Caldas JP, Vilela MM, Braghini CA, Mazzola TN, Marba ST. Antenatal maternal corticosteroid administration and markers of oxidative stress and inflammation in umbilical cord blood from very low birth weight preterm newborn infants. J Pediatr. 2012;88(1):61-6.

28. Souza MA, de Lourdes Brizot M, Biancolin SE, Schultz R, de Carvalho MHB, Francisco RPV, Zugaib M. Placental weight and birth weight to placental weight ratio in monochorionic and dichorionic growth-restricted and nongrowth-restricted twins. Clinics (Sao Paulo). 2017;72(5):265-71.

29. Negi R, Pande D, Kumar A, Khanna RS, Khanna HD. Evaluation of biomarkers of oxidative stress and antioxidant capacity in the cord blood of preterm low birth weight neonates. J Matern Fetal Neonatal Med. 2012;25(8):1338-41.

30. Michikawa T, Morokuma S, Fukushima K, Kato K, Nitta H, Yamazaki S. Maternal exposure to air pollutants during the first trimester and foetal growth in Japanese term infants. Environ Pollut. 2017;230:387-93.

\section{Publisher's Note}

Springer Nature remains neutral with regard to jurisdictional claims in published maps and institutional affiliations.

\section{Ready to submit your research? Choose BMC and benefit from:}

- fast, convenient online submission

- thorough peer review by experienced researchers in your field

- rapid publication on acceptance

- support for research data, including large and complex data types

- gold Open Access which fosters wider collaboration and increased citations

- maximum visibility for your research: over $100 \mathrm{M}$ website views per year

At $\mathrm{BMC}$, research is always in progress.

Learn more biomedcentral.com/submissions 